\title{
Synthesis of Polyolefin/Poly(methyl methacrylate) Block Copolymer Using Zirconocene Catalyst System
}

\author{
Yoshifumi FuKUI ${ }^{\dagger}$ and Masahide MuratA \\ Joint Research Center for Precision Polymerization (JRCPP), Japan \\ Chemical Innovation Institute (JCII), NIMC, 1-1 Higashi, Tsukuba, \\ Ibaraki 305-8565, Japan
}

(Received February 21, 2001; Accepted April 24, 2001)

\begin{abstract}
The reactions of methyl methacrylate (MMA) or $\mathrm{I}_{2}$ with the living zirconium-polyolefin bond (ZrPO) using zirconocene catalyst system were examined. Although the reaction of MMA with the living $\mathrm{Zr}$-PP does not proceed, $\mathrm{I}_{2}$ readily reacts with the living $\mathrm{Zr}-\mathrm{PO}$, such as atactic polypropylene (ataPP), iso poly(1-hexene) and syndiotactic poly(propylene) (synPP), quantitatively to give the terminal iodized polyolefins (PO-I). Moreover, PO-poly(methyl methacrylate) (PMMA) block copolymers could be obtained by the reaction of MMA with living Sm-PO, which was formerly prepared by the transformation of PO-I by $\mathrm{Cp}_{2}^{*} \mathrm{Sm}$.

KEY WORDS Poly(olefin)-block-Poly(methyl methacrylate) / Zirconocene Catalyst / Living Polymerization / Iodine / Samallocene /
\end{abstract}

Block copolymerizations of olefins with polar monomers remain an ultimate goal in the polyolefin chemistry. For that purpose, the reaction between living polyolefin and (meth)acrylate, such as MMA, has been investigated.

A block copolymerization of propylene with MMA by a $\mathrm{V}(\mathrm{acac})_{3} / \mathrm{AlEt}_{2} \mathrm{Cl}$ system ${ }^{1,2}$ and a block copolymerization of olefins $(\mathrm{C} 2,5,6)$ with (meth)acrylate, such as MMA, methyl acrylate (MA) and ethyl acrylate (EA), using lanthanocene complex ${ }^{3,4}$ may be the sole examples of this type of the reaction.

On lanthanide system, it has been also demonstrated the transformation of cationic growing center of poly(tetrahydrofuran) (PTHF) into anionic species directly by $\mathrm{SmI}_{2}$ using poly $(t \mathrm{BuMA})^{5 \mathrm{a}), b)}$ or indirectly by $\mathrm{KI} / \mathrm{Cp}_{2}^{*} \mathrm{Sm}$ using poly(alkyl methacrylate), such as MMA, ethyl methacrylate (EtMA), $i$ PrMA, $n$ BuMA. ${ }^{5 c)}$

Concerning group IV metallocene catalysts, Collins et al. described the living polymerization of MMA catalyzed by the two component system consisting of the cationic zirconocene complex and the neutral enolate complex. ${ }^{6 a)-c)}$ Shiono et al. reported that the cationic zirconocene complexes formed from dimethylzirconocenes and $\mathrm{B}\left(\mathrm{C}_{6} \mathrm{~F}_{5}\right)_{3}$ or $\mathrm{B}\left(\mathrm{C}_{6} \mathrm{~F}_{5}\right)_{4}{ }^{-}$ polymerize MMA in the well controlled manner when activated with the third component, such as alkyl zinc or alkyl aluminum compounds. ${ }^{7 \text { a) }}$ e)

Recently, Collins et al. published the first polymerization of MMA with a single component cationic zirconocene enolate complex. ${ }^{6 \mathrm{~d})}$ Gibson et al. have studied MMA polymerization with cationic zirconocene complexes formed from dimethylzirconocenes and

${ }^{\dagger}$ To whom correspondence should be addressed.
$\mathrm{B}\left(\mathrm{C}_{6} \mathrm{~F}_{5}\right)_{3} .{ }^{8}$ Höcker et al. showed that the cationic zirconocene complexes, for example, $\left(\mathrm{Me}_{2} \mathrm{C}\right) \mathrm{Cp}_{2} \mathrm{ZrMe}$ (thf) ${ }^{+} \mathrm{BPh}_{4}^{-}$or $\left(\mathrm{Me}_{2} \mathrm{C}\right) \mathrm{CpIndZrMe}$ (thf) ${ }^{+} \mathrm{BPh}_{4}^{-}$are active for living polymerization of MMA. ${ }^{9 a), b)}$

In previous communication, ${ }^{10 \mathrm{a}), \mathrm{b})}$ we showed that simple $\mathrm{Cp}_{2} \mathrm{ZrMe}_{2} / \mathrm{B}\left(\mathrm{C}_{6} \mathrm{~F}_{5}\right)_{3}$ system with or without $\mathrm{AlOct}_{3}$ as a scavenger promotes the living polymerization of propylene at $-78^{\circ} \mathrm{C}$, and that $\mathrm{rac}$-(Et)$\mathrm{Ind}_{2} \mathrm{ZrMe}_{2} / \mathrm{B}\left(\mathrm{C}_{6} \mathrm{~F}_{5}\right)_{3}$ system also promotes the isospecific living polymerization of 1 -hexene at $-78^{\circ} \mathrm{C}$. More recently, we also demonstrated that the syndiospecific living like polymerization of propylene takes place with mixed metallocene system, for example using $\left(\mathrm{Ph}_{2} \mathrm{C}\right)$ -

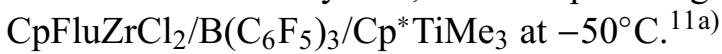

In this work, the reactions of MMA or $\mathrm{I}_{2}$ with the living $\mathrm{Zr}-\mathrm{PO}$ is investigated in order to make clear the reactivity of the "living" active sites of Zr-PO bonds to metallocene active species. PO-PMMA block copolymers with different type of stereospecificity in PO segment was synthesized, directly or indirectly.

\section{EXPERIMENTAL}

\section{Materials}

$\mathrm{Cp}_{2} \mathrm{ZrMe}_{2}, \mathrm{Cp}_{2} \mathrm{HfMe}_{2}$, rac-(Et)Ind $\mathrm{ZrMe}_{2}$, and $\left(\mathrm{Ph}_{2} \mathrm{C}\right) \mathrm{CpFluZrCl}_{2}$ were synthesized according to the procedure reported in the literature. ${ }^{12} \mathrm{Cp}^{*} \mathrm{TiMe}_{3}$ was purchased from Strem Chemicals Inc., tris(pentafluorophenyl) borane and trioctylaluminium were purchased from Tosoh-Akzo Chemical Co. and they were used without further purification. Propylene (from Takachiho Chemical Industrial Co. Ltd.) was purified through $\mathrm{NaOH}$ and $\mathrm{P}_{2} \mathrm{O}_{5}$. Toluene, 1-hexene, MMA 
Table I. Results of the MMA reaction with living PP or poly(1-hexene) end prepared with $\mathrm{Cp}_{2} \mathrm{ZrMe}_{2} / \mathrm{B}\left(\mathrm{C}_{6} \mathrm{~F}_{5}\right)_{3}$ or $\mathrm{Cp}_{2} \mathrm{HfMe}_{2} / \mathrm{B}\left(\mathrm{C}_{6} \mathrm{~F}_{5}\right)_{3}$ catalyst

\begin{tabular}{clcccc}
\hline Run & Temp $/{ }^{\circ} \mathrm{C}$ & Time $/ \mathrm{h}$ & Yield $/ \mathrm{mg}$ & $M_{\mathrm{n}}$ & $M_{\mathrm{w}} / M_{\mathrm{n}}$ \\
\hline 1 & -78 to 0 & 10 & 89.1 & 5200 & 1.08 \\
2 & -50 & 92 & 755 & $1130000 / 6200$ & $1.89 / 1.05$ \\
\hline
\end{tabular}

Polymerization conditions: Run 1: toluene $=13 \mathrm{~mL}, \mathrm{~B}=400 \mu \mathrm{mol}, \mathrm{Zr}=40 \mu \mathrm{mol}$, propylene $=83 \mathrm{mmol}$, temp $=-78^{\circ} \mathrm{C}$, time $=12 \mathrm{~h}$. Run 2: toluene $=9.5 \mathrm{~mL}, \mathrm{~B}=400 \mu \mathrm{mol}, \mathrm{Hf}=40 \mu \mathrm{mol}, 1$-hexene $=83 \mathrm{mmol}$, temp $=-50^{\circ} \mathrm{C}$, time $=29 \mathrm{~h}$. Reaction conditions: Run 1: MMA $=8 \mathrm{mmol}$. Run2: MMA $=80 \mathrm{mmol} . M_{\mathrm{n}}$ : Determined by GPC (THF at $40^{\circ} \mathrm{C}$ ) using PS standards.

was purified according to the usual procedure. Iodine was used without further purification.

\section{Reaction of the Living PO with MMA}

Polymerization of propylene was carried out in a $100 \mathrm{~mL}$ stainless steel autoclave by batchwise operation in toluene (total volume $=13 \mathrm{~mL})$. Borane $(360 \mu \mathrm{mol})$ as a scavenger was added, and the reactor was cooled in a methanol bath cooled to $-78^{\circ} \mathrm{C}$. After the addition of $\mathrm{Cp}_{2} \mathrm{ZrMe}_{2}$ and $\mathrm{B}\left(\mathrm{C}_{6} \mathrm{~F}_{5}\right)_{3}(\mathrm{Zr}=\mathrm{B}=40 \mu \mathrm{mol})$ to the reactor, the polymerization was started by introduction of liquid propylene $(83 \mathrm{mmol})$. And the polymerization was conducted for $12 \mathrm{~h}$, MMA ( $8 \mathrm{mmol})$ was added and the mixture was hold for $10 \mathrm{~h}$ by raising temperature from $-78^{\circ} \mathrm{C}$ to $0^{\circ} \mathrm{C}$. The mixture was quenched by addition of $\mathrm{HCl} /$ methanol solution. The polymer was washed with excess methanol and dried under vacuum at room temperature.

Polymerization of 1-hexene with $\mathrm{Cp}_{2} \mathrm{HfMe}_{2}$ at $-50^{\circ} \mathrm{C}$ and reaction of living poly(1-hexene) with MMA ( $80 \mathrm{mmol}$ ) was also conducted according to the same procedure as the case of propylene.

\section{Reaction of the Living $\mathrm{PO}$ with $\mathrm{I}_{2}{ }^{13}$}

Polymerization of propylene was conducted in an autoclave in toluene (total volume $=14.4 \mathrm{~mL}$ ). Trioctylaluminium $(800 \mu \mathrm{mol})$ as a scavenger was added, and the reactor was cooled in a methanol bath kept at -78 or $-50^{\circ} \mathrm{C}$. After the addition of zirconocene and $\mathrm{B}\left(\mathrm{C}_{6} \mathrm{~F}_{5}\right)_{3}(\mathrm{Zr}=\mathrm{B}=40 \mu \mathrm{mol})$ to the reactor (in the case with $\mathrm{Cs}$ symmetric zirconocene, $40 \mu \mathrm{mol}$ of $\mathrm{Cp}^{*} \mathrm{TiMe}_{3}$ was added), the polymerization was started by introduction of liquid propylene $(83 \mathrm{mmol})$. After the polymerization was conducted for a given time, $\mathrm{I}_{2}(3 \mathrm{mmol}) /$ toluene $(6 \mathrm{~mL})$ mixture was added to the reactor, followed by standing for $15 \mathrm{~h}$. The mixture was quenched by using methanol. The polymer produced was washed with excess methanol and dried under vacuum at room temperature.

Polymerization of 1-hexene with $\mathrm{C}_{2}$ symmetric zirconocene and reaction of living iso poly(1-hexene) with $\mathrm{I}_{2}$ were also conducted according to the same procedure as the case of propylene.

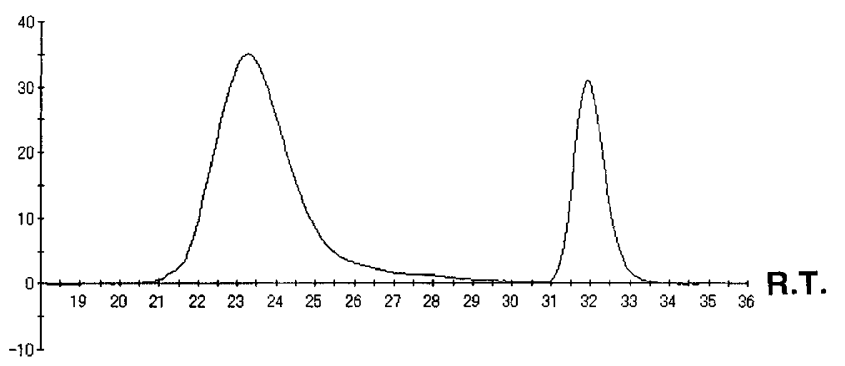

Figure 1. GPC curves for PP/PMMA (run2).

Reaction of the PO-I with $\mathrm{Cp}_{2}{ }_{2} \mathrm{Sm}$ and Block Copolymerization with MMA

The solution of ataPP-I $(4.2 \mu \mathrm{mol})$ in toluene was cooled at $0^{\circ} \mathrm{C}$. After the addition of the $\mathrm{Cp}^{*}{ }_{2} \mathrm{Sm}$ $(9 \mu \mathrm{mol}) /$ toluene solution, the mixture (total toluene volume $0.85 \mathrm{~mL}$ ) was stirred for $3 \mathrm{~min}$. The copolymerization was started by introduction of MMA $(0.9 \mathrm{mmol})$ at $0^{\circ} \mathrm{C}$, followed by standing for $1 \mathrm{~h}$. The mixture was quenched by addition of methanol.

Reaction of the iso poly(1-hexene)-I with $\mathrm{Cp}^{*}{ }_{2} \mathrm{Sm}$ and MMA were also conducted according to the same procedure as the case of ataPP-I.

\section{Analytical Procedure}

Molecular weights and molecular weight distributions of polymer were determined by GPC (TOSOH 8020 series) at $40^{\circ} \mathrm{C}$ using THF as eluent or HTGPC (TOSOH HLC-8121GPC/HT) at $135^{\circ} \mathrm{C}$ using $1,2,4-$ trichlorobenzene as eluent. ${ }^{1} \mathrm{H}$ and ${ }^{13} \mathrm{C}$ NMR spectra were recorded on a JEOL GSX series spectrometer operated at 270 and $68 \mathrm{MHz}$, respectively, in pulse Fourier transform mode. $\mathrm{CDCl}_{3}$ and tetrachloroethane- $d_{2}$ solvent were used for the NMR measurement.

\section{RESULTS AND DISCUSSION}

\section{Reaction of the Living PO with MMA}

Table I shows the results of the reaction of MMA with the living PP or poly(1-hexene) prepared with $\mathrm{Cp}_{2} \mathrm{ZrMe}_{2} / \mathrm{B}\left(\mathrm{C}_{6} \mathrm{~F}_{5}\right)_{3}$ or $\mathrm{Cp}_{2} \mathrm{HfMe}_{2} / \mathrm{B}\left(\mathrm{C}_{6} \mathrm{~F}_{5}\right)_{3}$ catalyst.

${ }^{1} \mathrm{H}$ NMR spectrum of run 1 is polypropylene homopolymer. ${ }^{14}$

Figure 1 shows the GPC result of run 2 which dis- 


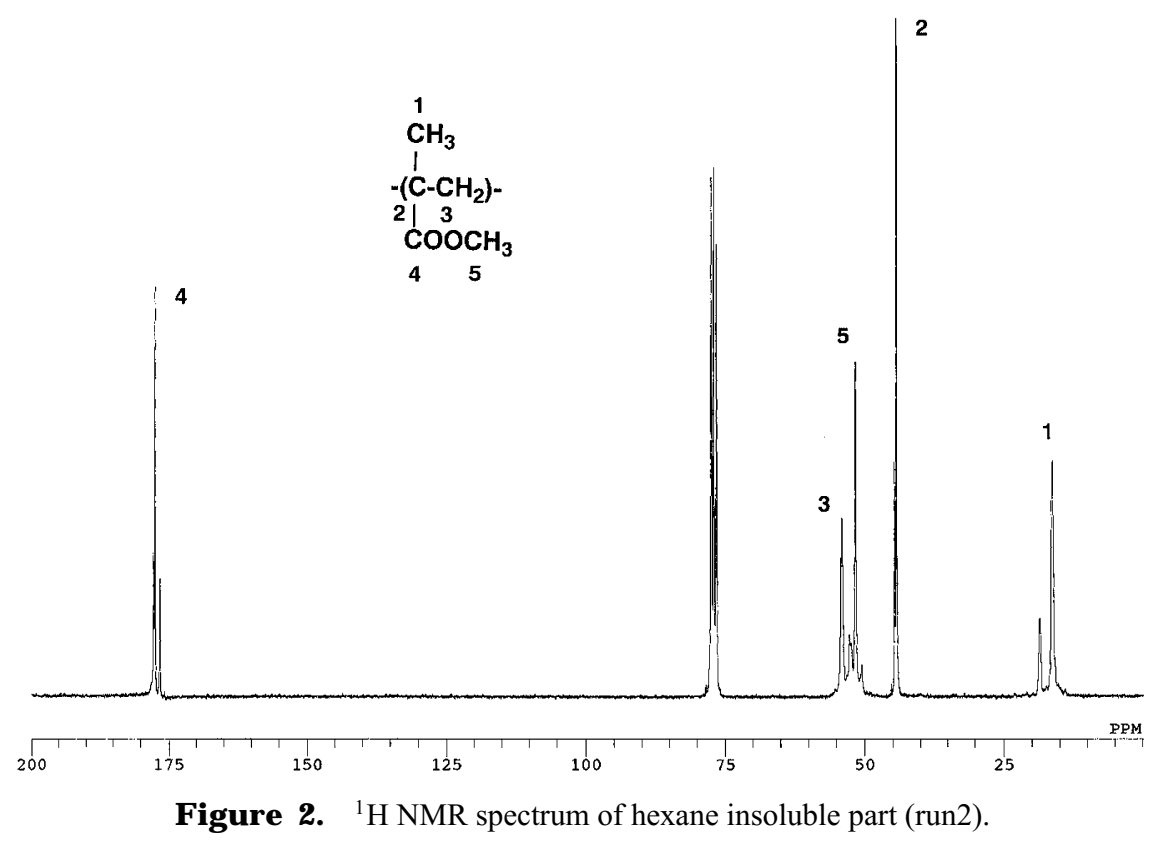

Table II. Results of the iodine reaction with living PO prepared with various metallocene catalyst systems

\begin{tabular}{clcccc}
\hline Run & Polymer & Yield $/ \mathrm{mg}$ & $M_{\mathrm{n}}$ & $M_{\mathrm{w}} M_{\mathrm{n}}$ & $M_{\mathrm{n}}\left({ }^{1} \mathrm{H}\right.$ NMR $)$ \\
\hline 3 & ataPP & 84.7 & 8400 & 1.19 & 8400 \\
4 & iso poly(1-hexene) & 47.8 & 4900 & 1.21 & 4600 \\
5 & synPP & 6.2 & 9700 & 1.37 & 10000 \\
\hline
\end{tabular}

Polymerization conditions: Run 3: toluene $=14.4 \mathrm{~mL}, \mathrm{Al}=800 \mu \mathrm{mol}, \mathrm{Zr}=\mathrm{B}=40 \mu \mathrm{mol}$, propylene $=83 \mathrm{mmol}$, temp $=-78^{\circ} \mathrm{C}$, time $=4 \mathrm{~h}$. Run 4: toluene $=11 \mathrm{~mL}, \mathrm{Al}=800 \mu \mathrm{mol}, \mathrm{Zr}=\mathrm{B}=40 \mu \mathrm{mol}, 1$-hexene $=83 \mathrm{mmol}$, temp $=-78^{\circ} \mathrm{C}$, time $=8 \mathrm{~h}$. Run 5: toluene $=14.4 \mathrm{~mL}, \mathrm{Al}=800 \mu \mathrm{mol}, \mathrm{Zr}=\mathrm{B}=\mathrm{Ti}=40 \mu \mathrm{mol}$, propylene $=83 \mathrm{mmol}$, temp $=-50^{\circ} \mathrm{C}$, time $=6 \mathrm{~h}$. Reaction conditions: Run 3, 4: $\mathrm{I}_{2}=3 \mathrm{mmol}$, temp $=-78^{\circ} \mathrm{C}$, time $=17,14 \mathrm{~h}$. Run 5: $\mathrm{I}_{2}=3 \mathrm{mmol}$, temp $=$ $-50^{\circ} \mathrm{C}$, time $=15 \mathrm{~h}$. Yield: Run 5: hexane insoluble fraction. $M_{\mathrm{n}}$ : Run 3, 5: Determined by HTGPC $\left(\mathrm{TCB}\right.$ at $\left.140^{\circ} \mathrm{C}\right)$ using PP standards. Run 4: Determined by GPC $\left(\mathrm{TCB}\right.$ at $\left.40^{\circ} \mathrm{C}\right)$ using PS standards.

plays bimodal molecular weight distribution (MWD) as shown in Table I. The lower molecular weight polymer shows a narrow MWD at around 1.05-1.1 (see Table I).

${ }^{1} \mathrm{H}$ NMR spectra of run 2 with low molecular weight shows poly(1-hexene) homopolymer soluble in hexane and that insoluble in hexane with high molecular weight is PMMA (Figure 2).

The number of polymer chains $(N)$ of $\mathrm{PHx}$ calculated from fractionated yield and $M_{\mathrm{n}}$ was $32 \mu \mathrm{mol}$, while that of $N$ value of PMMA was $0.5 \mu \mathrm{mol}$.

The $M_{\mathrm{n}}$ of the PHx obtained at early stage of polymerization increased with increasing polymerization time $\left(M_{\mathrm{n}}=1700 / 6600\right.$, MWD $1.13 / 1.05$ at $5 / 29 \mathrm{~h}$, respectively). ${ }^{15}$ However, the $M_{\mathrm{n}}$ at later stage did not increased $\left(M_{\mathrm{n}}=6200, \mathrm{MWD}=1.05\right.$ at $\left.92 \mathrm{~h}\right)$. Thus, the reaction of MMA with PO-Zr did not occur.

\section{Reaction of the Living $\mathrm{PO}$ with $\mathrm{I}_{2}$}

Run 3-5 in Table II are the results of the reaction of $\mathrm{I}_{2}$ at low temperature with living polyolefins prepared with various metallocene catalyst systems (run 3: ataPP with $\mathrm{Cp}_{2} \mathrm{ZrMe}_{2} / \mathrm{B}\left(\mathrm{C}_{6} \mathrm{~F}_{5}\right)_{3} / \mathrm{AlOct}_{3}$ at $-78^{\circ} \mathrm{C}$, run 4: iso poly (1-hexene) $[\mathrm{mmmm}=0.88]$ with rac-(Et) $\mathrm{Ind}_{2} \mathrm{ZrMe}_{2} / \mathrm{B}\left(\mathrm{C}_{6} \mathrm{~F}_{5}\right)_{3} / \mathrm{AlOct}_{3}$ at $-78^{\circ} \mathrm{C}$, run 5 : synPP [rrrr $=0.94]$ with $\left(\mathrm{Ph}_{2} \mathrm{C}\right) \mathrm{CpFluZrCl} 2 / \mathrm{B}_{2}\left(\mathrm{C}_{6} \mathrm{~F}_{5}\right)_{3} /$ $\mathrm{Cp}^{*} \mathrm{TiMe}_{3} / \mathrm{AlOct}_{3}$ at $\left.-50^{\circ} \mathrm{C}^{10,11 \mathrm{a}), \mathrm{b})}\right)$. All polyolefins obtained showed narrow MWDs.

To check the incorporation of iodine into the polymer end, ${ }^{1} \mathrm{H}$ NMR spectrum was measured. The run 3 in Table II shows the resonance attributable to methylene protons adjacent to iodine at around $3.1 \mathrm{ppm}$ (Figure 3), while the resonance attributable to a methine proton adjacent to iodine was not observed at around $4 \mathrm{ppm}$. Therefore, the polymerization of olefin is considered to proceed by the 1, 2-insertion.

The molecular weights were estimated from the relative intensity between the methylene chain end and the main chain $(0.25-1.75 \mathrm{ppm})$. The calculated values were almost the same as $M_{\mathrm{n}}$ s obtained by GPC (see Table II), which indicates that every living polyolefin chain reacts quantitatively with iodine to give PO-I. 


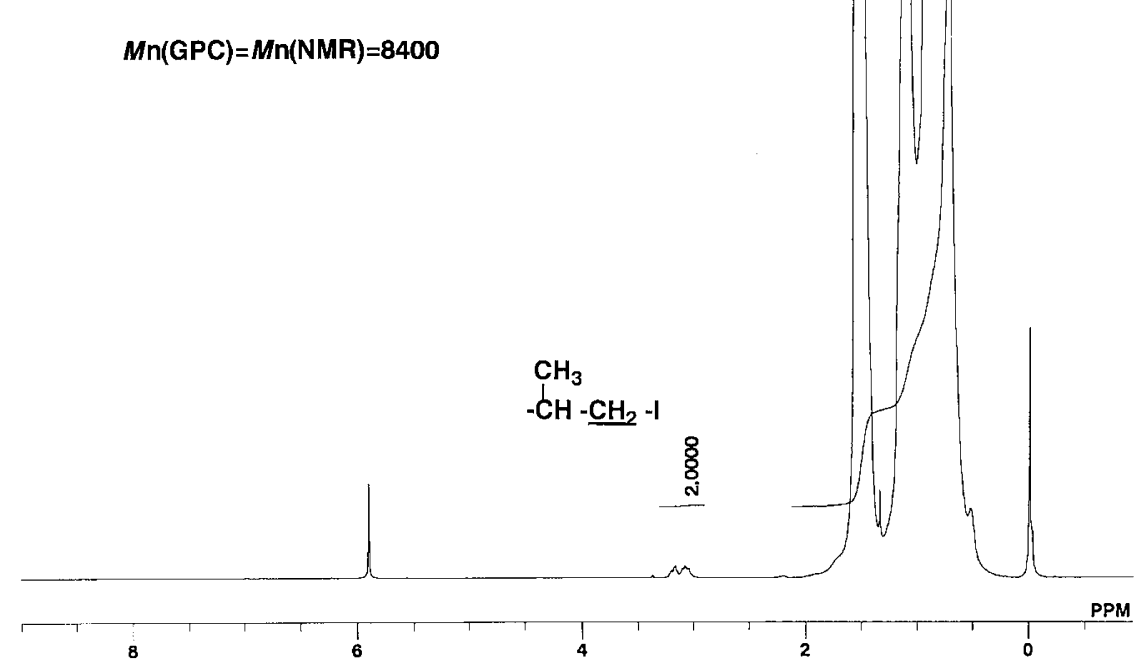

Figure 3. ${ }^{1} \mathrm{H}$ NMR spectrum of ataPP-I (run3).

Table III. Results of MMA copolymerization with PP-I via PP macroanion

\begin{tabular}{clccl}
\hline Run & Polymer & Yield $/ \mathrm{mg}$ & $M_{\mathrm{n}}$ & \multicolumn{1}{c}{$M_{\mathrm{w}} / M_{\mathrm{n}}$} \\
\hline 1 & ataPP $\left(M_{\mathrm{n}}=8400,35 \mathrm{mg}\right)$ & 114 & 26000 & 1.21 \\
& & 71.6 & 29500 & 1.10 (hex. insol.) \\
& 42.4 & 23600 & 1.18 (hex. sol.) \\
\hline
\end{tabular}

Reaction condition: Run 1: toluene $=0.85 \mathrm{~mL}$, ataPP-I $=4.2 \mu \mathrm{mol}, \mathrm{Sm}=9 \mu \mathrm{mol}$, temp $=0^{\circ} \mathrm{C}$. time $=3$ min. Copolymerization condition: Run 1: $\mathrm{MMA}=0.9 \mathrm{mmol}$, temp $=0^{\circ} \mathrm{C}$, time $=1 \mathrm{~h}$. Hexane soluble/insoluble fractionation condition: $\mathrm{THF} /$ hexane $=10 / 500 \mathrm{~mL} . M_{\mathrm{n}}$ : Determined by GPC $\left(\mathrm{THF}\right.$ at $\left.40^{\circ} \mathrm{C}\right)$ using PS standards.

Reaction of the PO-I with $\mathrm{Cp}_{2}{ }_{2} \mathrm{Sm}$ and Block Copolymerization with $M M A$

The results of MMA copolymerization with ataPP-I are given in Table III.

Figure 4 shows GPC profiles of several polymer samples. The curve a) is the GPC curve of the ataPP-I. The curve b) corresponds to the block copolymer of PP with PMMA before washing with hexane, i.e., the block copolymer is shifted toward higher molecular weight field and exhibites small shoulder. The GPC curve of the PP-block-PMMA after washing with hexane (curve c), i.e., hexane insoluble) shows a narrower MWD with very little shoulder.

Figure 5 shows $68 \mathrm{MHz}{ }^{13} \mathrm{C}$ NMR spectrum of the PP- $b$-PMMA before (Figure 5a) and after washing with hexane (Figure 5b). The content of PP in the block copolymer after washing with hexane is lower than the that of PP before washing with hexane. $\left({ }^{13} \mathrm{C}\right.$ NMR spectrum analysis confirms that the block copolymer is composed of ataPP and synPMMA [ $\mathrm{rr}=0.87$ ] segments in $25 \mathrm{~mol} \%: 75 \mathrm{~mol} \%$ ratio.)

Therefore, the shoulder shown in the crude product of Figure $4 \mathrm{~b}$ was mainly derived from not PMMA but

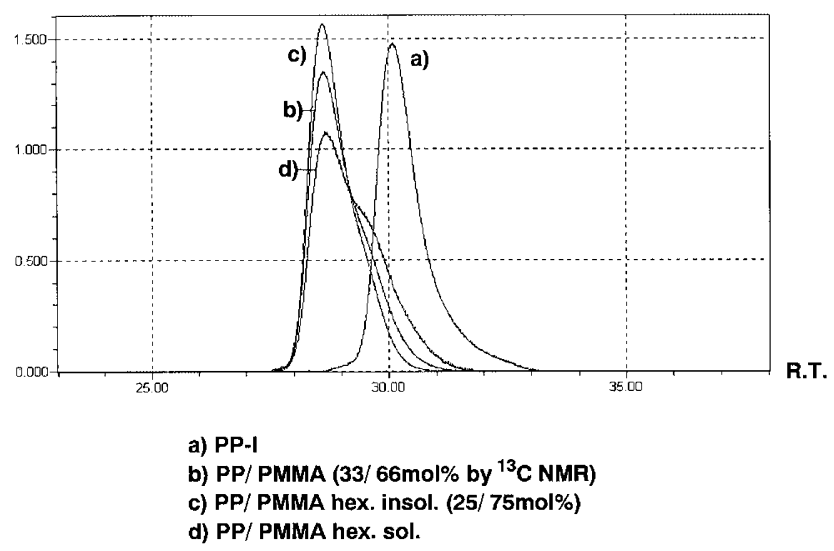

Figure 4. GPC profiles for ataPP-I, PP/PMMA before and after washing with hexane (run1).

PP homopolymer. Nomura et al. reported the presence of the coupling reaction of polymer-I with polymer- $\mathrm{S}_{\mathrm{m}}-$ $\mathrm{Cp}^{*}{ }_{2}$ as a main side reaction. ${ }^{5}$

The iso poly (1-hexene)-I $\left(M_{\mathrm{n}}=4900, \mathrm{MWD}=1.21\right)$ and isoPHx-block-synPMMA $\left(M_{\mathrm{n}}=8400 / 9300\right.$, MWD $=1.19 / 1.09$, before/after washing with hexane) were also produced. ${ }^{16}$

However, the preparation of synPP-block-synPMMA was not successful. In the case of synPP, the precipitation of the crystalline synPP-I took place. Synthesis of 
a)

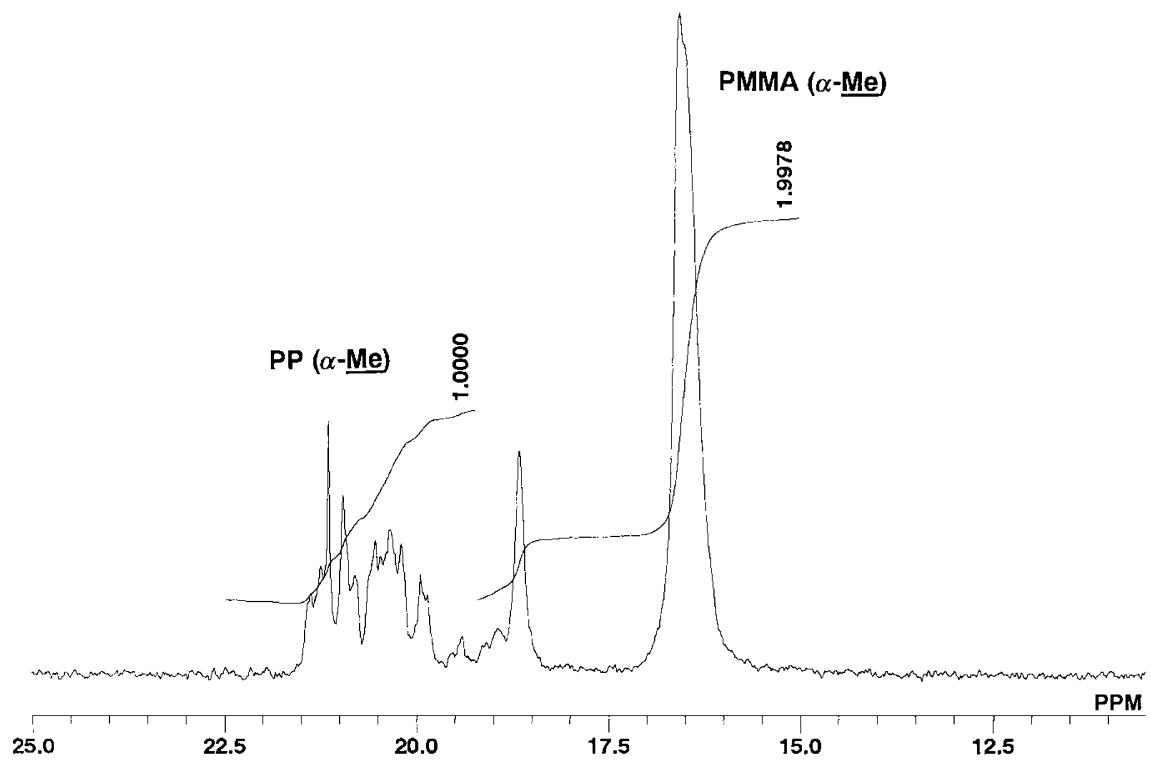

b)
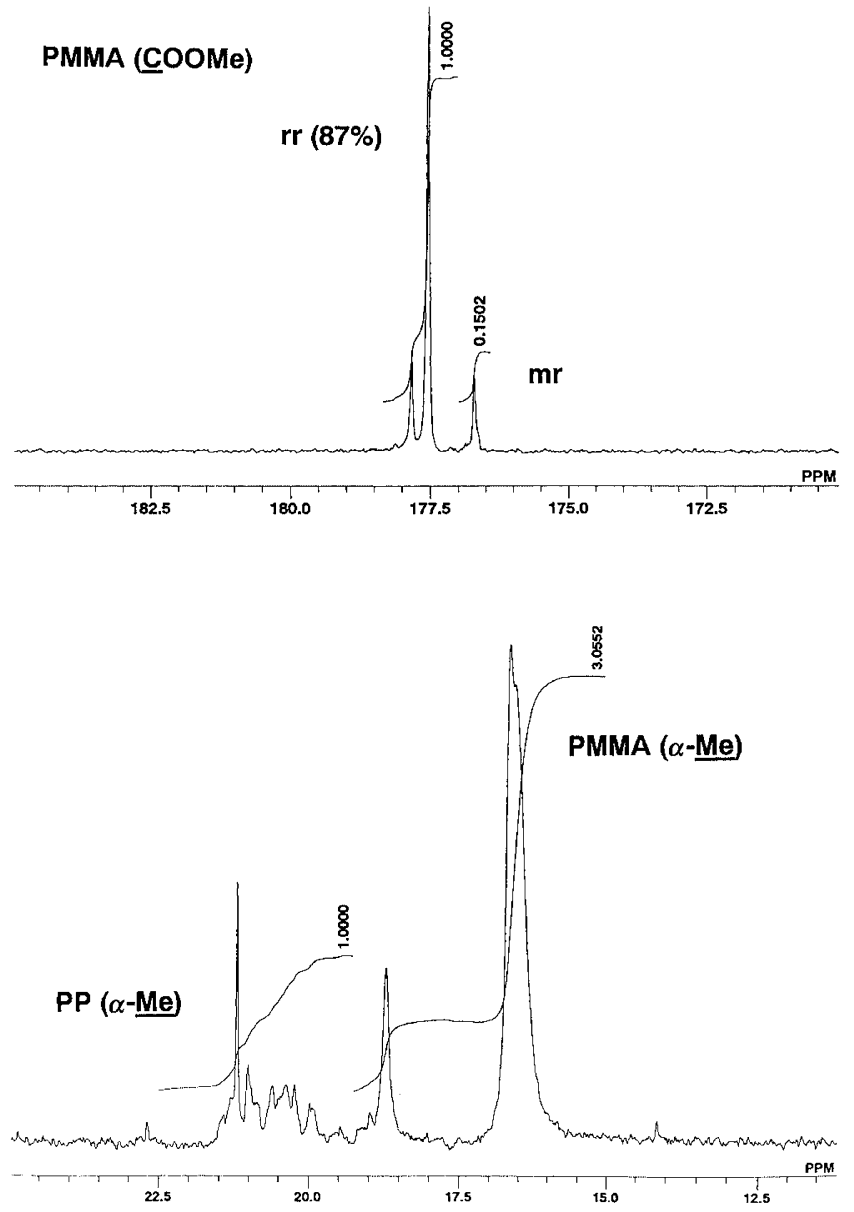

Figure 5. a) ${ }^{13} \mathrm{C}$ NMR spectrum of PP/PMMA before washing with hexane (run1). b) ${ }^{13} \mathrm{C}$ NMR spectrum of PP/PMMA after washing with hexane (run1). 
higher molecular weight PO-block-PMMA and its application will be our future work.

\section{CONCLUSIONS}

The reactions of methyl methacrylate (MMA) or $\mathrm{I}_{2}$ with the living zirconium-polyolefin bond (Zr-PO) using zirconocene catalyst system were conducted. Although the reaction of MMA with the living Zr-PP end do not proceed, iodine readily reacts with the living $\mathrm{Zr}$ $\mathrm{PO}$ end, such as ataPP, iso poly(1-hexene) and synPP, quantitatively to give the terminal iodized polyolefin (PO-I).

Moreover, PO-PMMA block copolymers could be obtained by the reaction of MMA with living Sm-PO, which was formerly prepared by the transformation of PO-I by $\mathrm{Cp}_{2}{ }_{2} \mathrm{Sm}$. Direct block copolymerization of living PO with MMA are under investigation.

Acknowledgment. This work was supported by NEDO for the project on Technology for Novel High Functional Materials in Industrial Science and Technology Frontier Program, AIST.

\section{REFERENCES}

1. Y. Doi, T. Koyama, and K. Soga, Makromol. Chem., 186, 11 (1985).

2. Y. Doi, M. Nunomura, N. Ohgizawa, and K. Soga, Makromol. Chem. Rapid Commun., 12, 245 (1991).

3. H. Yasuda, M. Furo, and H. Yamamoto, Macromolecules, 25, 5115 (1992).

4. G. Desurmont, T. Tokumitsu, and H. Yasuda, Macromolecules, 33, 7679 (2000).

5. a) R. Nomura, M. Narita, and T. Endo, Macromolecules, 27, 4853 (1994). b) R. Nomura, M. Narita, and T. Endo, Macromolecules, 27, 7011 (1994). c) R. Nomura, Y. Shibasaki, and T. Endo, J. Polym. Sci., PartA: Polym. Chem., 36, 2209 (1998)

6. a) S. Collins and D. G. Ward, J. Am. Chem. Soc., 114, 5460 (1992). b) S. Collins, D. G. Ward, and K. H. Suddaby, Macro- molecules, 27, 7222 (1994). c) Y. Li, D. G. Ward, S. S. Reddy, and S. Collins, Macromolecules, 30, 1875 (1997). d) H. Nguyen, A. P. Jarvis, M. J. G. Lesley, W. M. Kelly, S. S. Reddy, N. J. Taylor, and S. Collins, Macromolecules, 33, 1508 (2000).

7. a) H. Deng, T. Yano, T. Shiono, and K. Soga, Macromolecules, 27, 7938 (1994). b) H. Deng, T. Shiono, and K. Soga, Macromolecules, 28, 3067 (1995). c) H. Deng and T. Shiono, Macromol. Chem. Phys., 196, 1971 (1995). d) H. Deng and K. Soga, Macromolecules, 29, 1847 (1996). e) T. Shiono, T. Saito, N. Saegusa, H. Hagihara, T. Ikeda, H. Deng, and K. Soga, Macromol. Chem. Phys., 199, 1573 (1998).

8. P. A. Cameron, V. C. Gibson, and A. J. Graham, Macromolecules, 33, 4329 (2000).

9. a) T. Stuhldreier, H. Keul, and H. Höcker, Macromol. Rapid Commun., 21, 1093 (2000). b) H. Frauenrath, H. Keul, and H. Höcker, Macromolecules, 34, 14 (2001).

10. a) Y. Fukui, M. Murata, and K. Soga, Macromol. Rapid Commun., 20, 637 (1999). b) Y. Fukui and M. Murata, Macromol. Chem. Phys., (accepted).

11. a) Y. Fukui and M. Murata, Macromol. Chem. Phys., (submitted). b) The ataPP-I $\left(M_{\mathrm{n}}=14000 / 5500\right.$, MWD $\left.=1.09 / 1.12\right)$ were also obtained.

12. P. C. Wailes, H. Weigold, and A. P. Bell, J. Organomet. Chem., 34, 155 (1972). E. Samuel and M. D. Rausch, J. Am. Chem. Soc., 95, 6263 (1973). S. Collins, B. A. Kuntz, N. J. Taylor, and D. G. Ward, J. Organomet. Chem., 342, 21 (1988). F. R. W. P. Wild, M. Wasiucionek, G. Huttner, and H. H. Brintzinger, J. Organomet. Chem., 288, 63 (1985). J. C. W. Chien, W.-M. Tsai, and M. D. Raush, J. Am. Chem. Soc., 113, 8570 (1991).

13. Y. Doi, Y. Watanabe, S. Ueki, and K. Soga, Makromol. Chem. Rapid Commun., 4, 533 (1983).

14. Reaction of living poly(1-hexene) with MMA ( $8 \mathrm{mmol})$ for $13 \mathrm{~h}$ was also conducted $\left(M_{\mathrm{n}}=6700, \mathrm{MWD}=1.04\right) .{ }^{1} \mathrm{H}$ NMR spectrum was poly(1-hexene) homopolymer.

15. Polymerization of 1 -hexene for $65 \mathrm{~h}$ was also conducted $\left(M_{\mathrm{n}}\right.$ $=12100, \mathrm{MWD}=1.06$ ). The $M_{\mathrm{n}}$ of the PHx increased with increasing polymerization time and MWD was narrow. Therefore, the living nature of poly(1-hexene) was kept at longer polymerization time.

16. The ataPP-I $\left(M_{\mathrm{n}}=14000\right.$, MWD $\left.=1.09\right)$ and ataPP- blocksynPMMA $\left(M_{\mathrm{n}}=20000, \mathrm{MWD}=1.16\right)$ were also obtained. 